\title{
Fostering an Attitude of Nationalism to the Students of SMP Negeri Panjatan Through the Philosophical Value of Batik Gebleg Renteng Toward the Values of Pancasila
}

\author{
Andi Andoko', Warto², Djono ${ }^{3}$ \\ Pascasarjana Pendidikan Sejarah, Universitas Sebelas Maret, Surakarta, Indonesia ${ }^{1,2,3}$ \\ andiandoko82@gmail.com ${ }^{1}$, warto_file@yahoo.com², djono_sk@yahoo.com³
}

\section{Article History}

accepted 23/03/2021

approved 10/04/2021

published 20/04/2021

\begin{abstract}
This study aims to foster the nationalistic attitude of students of SMP Negeri Panjatan, Kulon Progo Regency, Yogyakarta Special Region through the philosophical values of Gebleg Renteng related to Pancasila values. This research uses descriptive qualitative method. The data sources are taken from books, journals and supporting documents related to research. The main characteristics in the research come from the natural / reality background at Panjatan State Junior High School by observing, interviewing, and analyzing documents. After the data is collected, the researcher analyzes and then concludes the results of the data that have been obtained. The results of this study are the motifs in the Gebleg Renteng batik, including Gebleg in the form of a figure eight combined into one bond (jointly), the kacer bird, the mangosteen fruit, the binangun symbol, the Kulon Progo logo, up and down patterns and other variations. Gebleg Renteng's batik motif can be taken from a philosophical value, namely nationalism. Values are always associated with moral ethics or character so that the philosophical values in Gebleg Renteng's batik can be used to foster students' nationalistic attitudes through learning. An attitude of nationalism must be instilled in the younger generation in order to understand the importance of the Indonesian struggle for independence. The value contained in Gebleg Renteng's batik is nationalism in accordance with what is the basis of the Republic of Indonesia, namely Pancasila. Pancasila is an Indonesian state ideology which has very meaningful values in building the nation and state. Pancasila is taken from the values of customs, cultural and religious values that exist in the life of the Indonesian people so that Pancasila must be maintained for the integrity of the Unitary State of the Republic of Indonesia.
\end{abstract}

Keywords: nationalism, values, Gebleg Renteng batik, Pancasila

\begin{abstract}
Abstrak
Penelitian ini bertujuan untuk menumbuhkan sikap nasionalisme siswa SMP Negeri Panjatan, Kabupaten Kulon Progo, Daerah Istimewa Yogyakarta melalui nilai filosofi Gebleg Renteng berkaitan dengan nilai-nilai pancasila. Penelitian ini menggunakan metode kualitatif deskriptif. Adapun sumber data diambil dari buku, jurnal dan dokumen pendukung yang berkaitan dengan penelitian. Karateristik utama dalam penelitian berasal dari latar belakang alami/kenyataan di SMP Negeri panjatan dengan melakukan pengamatan, wawancara, dan penelaah dokumen. Setelah data terkumpul selanjutnya peneliti menganalisa kemudian menyimpulkan hasil data yang sudah didapatkan. Hasil dari penelitian ini adalah motif dalam batik Gebleg Renteng diantaranya Gebleg berbentuk angka delapan yang digabung menjadi satu ikatan (renteng), burung kacer, buah manggis, lambang binangun, logo Kulon Progo, pola naik turun dan variasi lainnya. Motif batik Gebleg Renteng dapat diambil nilai filosofi yaitu nasionalisme. Nilai selalu dikaitkan dengan etika moral atau budi perkerti sehingga nilai filosofi dalam batik Gebleg Renteng dapat dijadikan untuk menumbuhkan sikap nasionalisme siswa melalui pembelajaran. Sikap nasionalisme harus ditanamkan kepada generasi muda agar mengerti betapa pentingnya perjuangan bangsa Indonesia dalam merebut kemerdekaan. Nilai yang terdapat dalam batik Gebleg Renteng yaitu nasionalisme sesuai dengan apa yang menjadi dasar negara Republik Indonesia yaitu pancasila. Pancasila merupakan suatu ideologi negara Indonesia yang mempunyai nilai-nilai yang sangat bermakna dalam membangun bangsa dan negara. Pancasila diambil dari nilai adat-istiadat, nilai kebudayaan serta religius yang terdapat dalam kehidupan masyarakat Indonesia sehingga pancasila harus tetap dijaga demi keutuhan Negara Kesatuan Republik Indonesia.
\end{abstract}

Kata kunci : nasionalisme, nilai, batik Gebleg Renteng, Pancasila

Social, Humanities, and Education Studies (SHEs): Conference Series https://jurnal.uns.ac.id/shes

p-ISSN 2620-9284 e-ISSN 2620-9292 


\section{PENDAHULUAN}

Kurikulum pendidikan yang digunakan di Indonesia saat ini adalah Kurikulum 2013. Kurikulum ini diarahkan untuk memperdayakan semua potensi yang dimiliki oleh siswa agar dapat memiliki kompetensi yang seimbang antara sikap/attitude, pengetahuan/knowledge, dan ketrampilan/skill. Selain itu, Kurikulum 2013 diharapkan melahirkan siswa yang kreatif, produktif, inovatif, dan afektif melalui penguatan ranah sikap, ketrampilan dan pengetahuan yang terintegrasi. Kurikulum ini juga bertujuan untuk mendorang siswa agar mampu lebih baik dalam melakukan observasi, memiliki ketrampilan bertanya, memiliki daya nalar dan dapat mengkomunikasikan/mempresentasikan apa yang diperoleh/diketahui setelah siswa menerima materi pembelajaran di sekolah (Hosnan, 2014:2).

Kurikulum 2013 diharapkan siswa mempunyai sikap yang bisa menjadikan bangsa yang maju, bangsa yang modern, bangsa yang aman, damai, adil dan sejahtera sesuai dengan nilai-nilai yang terkandung dalam pancasila. Sebagai bangsa dan negara yang berdaulat membutuhkan identitas kebangsaan (Nasionalisme) bagi warga negara Indonesia khususnya di kalangan generasi muda. Sikap nasionalisme dibutuhkan bagi warga negara atau generasi muda agar berperilaku positif untuk bangsa dan negara sesuai dengan pancasila. Sekarang ini dikalangan generasi muda khususnya siswa sikap nasionalisme sudah mulai luntur dan masih belum sepenuhnya mengamalkan nilai-nilai pancasila.

Sikap nasionalisme siswa yang mulai luntur dapat dilihat dari cara siswa yang kurang mengindahkan peraturan dan tata tertib sekolah, siswa kurang disiplin terhadap waktu, kurang memelihara keindahan dan kebersihan lingkungan, sikap yang belum sepenuhnya khidmat dalam mengikuti upacara bendera, siswa kurang menghargai dan mengenang jasa para pahlawan. Selain itu, rasa persaudaraan siswa yang semakin menipis dimana siswa bersikap acuh tak acuh terhadap siswa lain. Masih banyak siswa yang lebih mementingkan diri sendiri dan kelompoknya dibandingkan kepentingan umum, memilih-milih dalam berteman serta kurangnya rasa kepedulian sosial terhadap teman sehingga kurangnya kesediaan kerelaan berkorban untuk memberikan bantuan atau sumbangan terhadap orang yang terkena musibah.

Sikap nasionalisme yang semakin luntur kalau dibiarkan begitu saja dapat mengancam dan menghancurkan bangsa dan negara. Negara akan menjadi lemah dikarenakan generasi muda tidak memahami tentang nasionalisme yang sesuai dengan nilai-nilai pancasila. Hal ini akan sangat mudah bagi pihak asing untuk memasukkan budaya mereka ke dalam negara Indonesia. Masuknnya budaya asing ke Indonesia akan berpengaruh terhadap akulturasi, bahkan menghilangnya kebudayaan dan kepribadian bangsa yang merupakan jati diri bangsa. Oleh sebab itu, sikap nasionalisme harus ditumbuhkan kepada generasi muda agar Indonesia tetap terjaga sebagai Negara Kesatuan Republik Indonesia sesuai dengan pancasila.

Upaya untuk menumbuhkan sikap nasionalisme salah satunya melalui dunia pendidikan dengan mempelajari tentang nilai filosofi yang ada dalam batik Gebleg Renteng di Kulon Progo. Batik Gebleg Renteng menjadi cara untuk menumbuhkan sikap nasionalisme siswa SMP Negeri Panjatan dikarenakan dalam motif batik Gebleg Renteng mempunyai nilai nasionalisme di dalammnya. Batik ini adalah hasil karya Ales Candra Wibawa di Dlaban rt 08/rw 04, Sentolo, Sentolo, Kulon Progo. Batik Gebleg Renteng merupakan batik Khas yang berasal dari kabupaten Kulon Progo, Daerah Istimewa Yogyakarta.

Teori

Sikap berawal dari perasaan suka atau tidak suka yang berkaitan dengan kecenderungan seseorang dalam merespon suatu obyek. Sikap sebagai ekspresi dari nilai-nilai atau pandangan hidup seseorang yang memiliki tiga komponen yaitu afektif, kognitif, dan konatif. Afektif adalah perasaan yang dimiliki seseorang atau penilaiannya terhadap suatu obyek. Kognitif merupakan kepercayaan atau keyakinan seseorang 
mengenai obyek. Konatif adalah kecenderungan untuk berperilaku dengan cara-cara tertentu yang berkenaan dengan kehadiran obyek sikap (Hosnan, 2014: 419).

Nasionalisme berasal dari kata nation yang berarti bangsa. Bangsa dalam antropologi dan sosiologi adalah suatu persekutuan hidup masyarakat yang berdiri sendiri dan masing-masing anggota tersebut merasa memiliki satu kesatuan ras, bahasa, agama, sejarah, dan adat istiadat. Bangsa dalam pengertian politis adalah masyarakat dalam suatu daerah yang sama dan tunduk kepada kedaulatan negaranya sebagai suatu kekuasaan tertinggi ke luar dan ke dalam (Yatim, 1999:57).

Batik secara etimologi berasal dari basaha Jawa, "amba" yang berarti lebar, luas, kain; dan motif (kata kerja membuat titik) yang berkembang menjadi istilah "batik". Pengertian batik yaitu menghubungkan titik-titik menjadi gambar tertentu pada kain yang luas dan lebar. Arti lainya adalah segala sesuatu yang berhubungan dengan membuat titik-titik tertentu pada kain mori. Batik dalam bahasa Jawa ditulis dengan "bathik" yang mengacu pada huruf "tha" artinya rangkaian dari titik-titik yang membentuk gambaran tertentu (Wulandari, 2011:4).

Nilai atau value termasuk bidang kajian filsafat. Filsafat sering diartikan sebagai ilmu tentang nilai-nilai. Istilah nilai di dalam ilmu filsafat dipakai untuk menunjuk kata benda abstrak yang artinya "keberhargaan" (Worth) atau kebaikan (goodness) dan kata kerja yang artinya suatu kejiwaan tertentu dalam menilai atau melakukan penilaian. Nilai dalam Dictionary of Sosciology and Related Sciences adalah kemampuan yang dipercayai pada suatu benda untuk memuaskan manusia. Nilai pada hakikatnya adalah sifat atau kualitas yang melekat pada suatu objek, bukan objek itu sendiri. Sesuatu mengandung nilai artinya ada sifat atau kualitas yang melekat pada sesuatu itu (Kaelan, 2010:87).

\section{METODE}

Metode penelitian ini menggunakan kualitatif deskriftif. Data diperoleh dari buku, jurnal, artikel dan dokumen yang mendukung penelitian. Sumber data diambil dari wawancara Kepala sekolah, Guru, dan siswa kelas VIII SMP Negeri 1 Panjatan dan SMP Negeri 2 panjatan Kabupaten Kulon Progo.

Teknik Pengumpulan data dalam penelitian ini menggunakan metode observasi dan interviu (wawancara). Observasi dilakukan secara langsung di SMP Negeri 1 Panjatan dan SMP Negeri 2 Panjatan. Kegiatan observasi ini untuk mengamati tentang bagaimana proses belajar mengajar, karakteristik siswa dalam hal sikap nasionalisme. Wawancara dalam penelitian ini dilaksanakan secara lisan dalam pertemuan tatap muka dengan Kepala sekolah, guru dan siswa. Wawancara dilakukan di dua sekolahan yaitu SMP Negeri 1 Panjatan dan SMP Negeri 2 Panjatan. Informan wawancara adalah Kepala Sekolah yaitu bapak Sugeng Widodo, S.Pd.,M.Pd. dan dua guru mata pelajaran IPS yaitu Ibu Dra. H. Wuryanti Eko Wahyuni, S.Pd serta bapak Tri Martono, S.Pd. di SMP Negeri 1 Panjatan. Sedangkan di SMP Negeri 2 Panjatan yaitu dengan Ibu Sri Yuwanti, S.Pd., M.Pd. selaku kepala Sekolah dan guru mata pelajaran IPS Ibu Ety Sukristiyanti, S.Pd.

\section{A. Analisis Kebutuhan di SMP Negeri panjatan}

\section{HASIL DAN PEMBAHASAN}

Berdasarkan hasil observasi dan wawancara yang dilakukan di SMP Negeri 1 panjatan dan SMP Negeri 2 Panjatan pada bulan Oktober 2020 bahwa menurut bapak Sugeng Widodo, S.Pd., M.Pd. kepala sekolah SMP Negeri 1 Panjatan diperlukan suatu materi atau bahan ajar yang inovatif yang berkaitan dengan batik Gebleg Renteng dikarenakan selama ini belum ada bahan ajar yang menulis tentang nilai filosofi dalam batik tersebut. Siswa selama ini belum terlalu paham 
tentang nilai apa yang terkandung dalam batik Gebleg Renteng meskipun siswa sudah praktik membuat batik tersebut dalam ketrampilan seni rupa. Hal senada disampaikan oleh bapak Tri Martono, S.Pd. Guru IPS SMP Negeri 1 Panjatan selama ini siswa sudah praktik membuat batik Gebleg Renteng tetapi belum ada bahan ajar yang membahas secara detail tentang nilai filosofi yang ada di dalam batik tersebut, sehingga diperlukan materi khusus yang membahas batik Gebleg Renteng agar siswa lebih paham tentang nilai-nilai yang terkandung di dalamnya.

Wawancara dengan Ibu Sri Yuwanti, S.Pd., M.Pd. selaku kepala sekolah SMP Negeri 2 Panjatan mengatakan bahwa sebagian siswa belum mengerti tentang motif dan nilai filosofi yang ada dalam batik Gebleg Renteng. Selain itu siswa belum diajarkan secara detail tentang batik Gebleg Renteng yang merupakan batik khas Kulon Progo. Sedangkan menurut Ibu Ety Sukristiyanti, S.Pd. mengatakan batik Gebleg Renteng perlu disosialisasikan kepada siswa agar mengerti tentang arti atau makna dari batik tersebut sehingga nilai dari batik Gebleg Renteng dapat diaplikasikan dalam kehidupan sehari-hari.

Wawancara dengan beberapa siswa di SMP Negeri Panjatan masih banyak siswa yang belum mengerti tentang motif apa saja yang ada dalam batik Gebleg Renteng. Mereka hanya mengerti nama dari batik Gebleg Renteng karena setiap satu minggu sekali dipakai buat seragam sekolah. Siswa belum mengerti tentang sejarah adanya batik Gebleg Renteng, siapa yang mendesain batik tersebut dan belum mengerti nilai filosofi apa yang terkandung di dalamnya.

Berdasarkan hasil wawancara dari kepala sekolah dan guru serta siswa di SMP Negeri Panjatan dapat diambil kesimpulan bahwa memerlukan suatu bahan ajar yang inovatif yang memuat materi tentang batik Gebleg Renteng. Mengajarkan kepada siswa tentang motif dan filosofi dari batik Gebleg Renteng agar mengerti tentang budaya kearifan lokal yang dimiliki oleh kabupaten Kulon Progo berupa batik. Menanamkan nilai yang terkandung dalam batik Gebleg Renteng yaitu sikap nasionalisme kepada siswa agar peduli tentang budaya batik di wilayah kabupaten Kulon Progo.

\section{B. Nasionalisme dalam Nilai filosofi batik Gebleg Renteng}

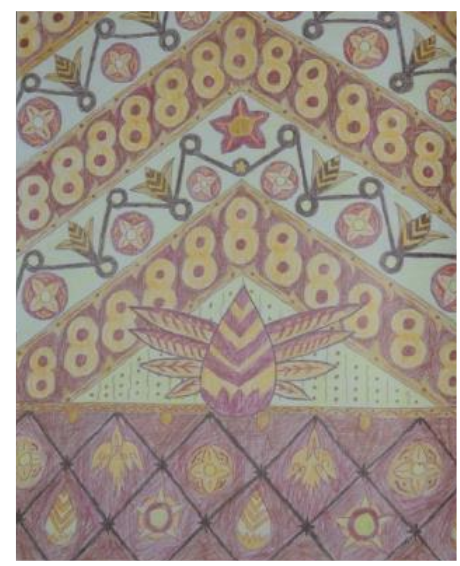

Gambar 1. Desain Batik Gebleg Renteng karya Ales Candra Wibawa (Sumber: Dokumen Andi Andoko)

Batik Gebleg Renteng merupakan kearifan lokal yang dimiliki oleh kabupaten Kulon Progo. Awalnya gagasan mengenai corak batik khas Kulon Progo disampaikan oleh Bupati Kulon Progo dr. Hasto Wardoyo, Sp.OG (K) saat Audensi FORMI (Federasi Olah Raga Rekreasi Masyarakat Indonesia) pada tanggal 8 Desember 2011. Kemudian ditindak lanjuti dengan mengadakan lomba desain 
batik khas Kulon Progo Tingkat Nasional. Pada hari Minggu 6 Mei 2012 diumumkan secara resmi melalui berbagai media hasil dari lomba desain motif batik khas Kulon Progo tingkat Nasional, dengan nominator terbaik yaitu "Gebleg Renteng". Batik Gebleg Rengteng tersebut dijadikan motif khas di Kulon Progo merupakan hasil karya Ales Candra Wibawa yang bertempat tinggal di Sentolo, Sentolo, Kulon Progo, Daerah Istimewa Yogyakarta (Silitonga, 2017:37).

Motif Batik Gebleg Renteng terdiri dari Gebleg yang di renteng-renteng, buah manggis, lambang binangun, logo Kulon Progo, burung kacer, pola naik turun dan variasi lainnya. Motif Gebleg digambar dalam jumlah banyak dan disusun berjajar (Renteng). Motif Gebleg terinspirasi dari makanan khas yang berasal dari Kabupaten Kulon Progo yang bernama Gebleg. Gebleg merupakan makanan yang terbuat dari ketela/ubi kayu dicampur dengan tepung tapioka dibuat secara bulatbulat seperti angka delapan yang berwarna putih. Renteng adalah ikatan satu sama lain atau jajaran dalam bahasa Jawa. Renteng mempunyai pengertian bahwa ikatan dari berbagai elemen masyarakat yang dijadikan satu padu dengan semangat kegotongroyongan, kekompakan, saling bekerja sama serta saling peduli terhadap sesama manusia sehingga terwujud sebuah persatuan dan kesatuan (Aman, 2014:92).

Lambang binangun merupakan slogan dari kabupaten Kulon Progo. Binangun adalah singkatan dari Beriman, Indah, Nuhoni, Aman, Nalar, Guyub, Ulet, Nyaman. Motif logo Kulon Progo adalah simbolisasi dari Logo kabupaten Kulon Progo. Motif logo Kulon Progo dibuat lebih sederhana dari bentuk Aslinya. Makna dari logo Kulon Progo yaitu bentuk bintang segi lima merupakan landasan idiil perjuangan yaitu falsafah Pancasila. Lingkaran melambangkan bahwa dengan falsafah pancasila semua lapisan dan aliran serta keyakinan dapat dipersatukan. Kulon Progo mempunyai berbagai bahan makanan pokok seperti Padi, kapas kelapa dan cengkeh serta daerahnya berupa dataran rendah, daerah pegunungan dan pantai. Selain itu, ada tiga sungai besar, yaitu sungai Progo, sungai Serang dan sungai Bogowonto, lukisan nyala juplak (pelita Tradisional) artinya jiwa dan semangat pantang mundur (https://kulonprogokab.go.id/v31/detil/7687/identitasdaerah).

Motif kuncup bunga mekar mempunyai makna Kulon Progo merupakan daerah yang sedang berkembang dalam pembangunan disegala bidang baik dalam politik, sosial, ekonomi, pendidikan dan lainnya. Selain itu, makna dari motif tersebut adalah Kulon Progo mempunyai daerah yang indah sesuai dengan branding Kulon Progo "The Jewel of Java" artinya permata dari pulau Jawa.

Motif buah manggis merupakan khas flora dari Kulon Progo. Buah manggis banyak terdapat di dataran tinggi daerah kokap kabupaten Kulon Progo. Rasa dari buah manggis yaitu manis dan asam yang mempunyai kandungan nutrisi diantaranya vitamin C, Vitamin B2, folat, magnesium dan xanthoses. Kandungan nutrisi tersebut bermanfaat untuk meningkatkan daya tahan tubuh, menurunkan berat badan mencegah penyakit kanker, mengontrol kadar gula darah dan meredakan radang sendi.

Gambar burung kacer yang terbang ke atas, burung kacer merupakan salah satu fauna khas yang ada di Kulon Progo. Habitat burung kacer berada di hutan yang ada di kecamatan Kokap, kabupaten Kulon Progo. Burung kacer merupakan burung kicau yang gemar memakan serangga. Ciri dari burung kacer mempunyai ukuran kecil, bulu berwarna hitam diseluruh tubuh kecuali pada bagian sayap sebagian berwarna putih dan bagian dada berwarna putih. Burung kacer dijadikan ikon dalam batik Gebleg Renteng dikarenakan mempunyai suara merdu dan indah serta hidup berkembang di daerah Kulon Progo (Aman, 2014:97-100).

Motif batik Gebleg Renteng lainnya yaitu motif arah naik turun mempunyai makna sebagai perlambang keindahan alam di Kulon Progo. Kulon Progo 
mempunyai wilayah yang terdiri dari dataran tinggi, dataran rendah dan pantai. Dataran tinggi terletak di daerah utara yang meliputi pegunungan menoreh terdiri dari kecamatan Kokap, Nanggulan, Girimulyo, Kalibawang dan Samigaluh. Sedangkan dataran rendah terdiri dari kecamatan Wates, Temon, Panjatan, Lendah, dan Galur. Pantai terletak disebelah paling selatan yaitu pantai Congot, Glagah, Bugel dan Trisik (www.motifbatik.web.id/2019/01/filosofi-dan-sejarah-batikmotif-geblek.html?m=1).

Penjelasan tentang nilai yang dapat diambil dari batik Gebleg Renteng tentang sikap nasionalisme sebagai berikut:

\begin{tabular}{|c|c|c|}
\hline No & Motif & Nilai Sikap Nasionalisme \\
\hline 1. & Gebleg & $\begin{array}{c}\text { Rasa bangga terhadap makanan lokal, peduli makanan } \\
\text { lokal }\end{array}$ \\
\hline 2. & Renteng & $\begin{array}{l}\text { Persatuan dan kesatuan, kebersamaan, gotong royong, } \\
\text { kepedulian masyarakat, rasa sayang, kerja sama }\end{array}$ \\
\hline 3. & $\begin{array}{l}\text { Burung } \\
\text { kacer }\end{array}$ & $\begin{array}{l}\text { Peduli terhadap fauna lokal, rasa bangga terhadap } \\
\text { fauna lokal, melestarikan hewan }\end{array}$ \\
\hline 4. & $\begin{array}{l}\text { Buah } \\
\text { manggis }\end{array}$ & $\begin{array}{l}\text { Peduli terhadap flora lokal, melestarikan tumbuhan, rasa } \\
\text { bangga terhadap buah lokal }\end{array}$ \\
\hline 5. & $\begin{array}{l}\text { Lambang } \\
\text { binangun }\end{array}$ & $\begin{array}{c}\text { Persatuan dan kesatuan, keyakinan agama, } \\
\text { ketentraman, harmonis, tidak putus asa, kerja keras, } \\
\text { kemakmuran }\end{array}$ \\
\hline 6. & $\begin{array}{l}\text { Logo } \\
\text { Kulon } \\
\text { Progo }\end{array}$ & $\begin{array}{c}\text { Cinta tanah air, persatuan dan kesatuan, perekonomian, } \\
\text { kesejahteraan masyarakat, ketahanan pangan, pantang } \\
\text { mundur }\end{array}$ \\
\hline 7. & $\begin{array}{l}\text { Pola naik } \\
\text { turun }\end{array}$ & $\begin{array}{l}\text { Peduli tentang kekayaan alam, perekonomian, } \\
\text { pariwisata }\end{array}$ \\
\hline
\end{tabular}

Tabel 1. Nasionalisme dalam batik Gebleg Renteng (Sumber: Dokumen Andi Andoko)

\section{Nasionalisme terhadap Nilai-nilai Pancasila}

Istilah Nasionalisme berasal dari bahasa latin yaitu natio yang berarti bangsa yang dipersatukan karena kelahiran, dan nasci mempunyai pengertian dilahirkan, sehingga nasionalisme dapat diartikan sebagai bangsa yang bersatu karena faktor kelahiran yang sama (Muttaqin, 2006:22). Nasionalisme menurut Sartono Kartodirjo dalam suatu negara kebangsaan dijiwai dengan prinsip-prinsip nasionalisme diantaranya : Kesatuan, Kebebasan, Kesamaan, Kepribadian, dan Prestasi. Prinsip yang Pertama, Kesatuan (Unity) dalam hal wilayah, bangsa, bahasa, ideologi, pemerintahan, perekonomian, pertahanan, keamanan; Kedua, Kebebasan (freedom, liberty, independence) meliputi beragama, berbicara, berkelompok, dan berorganisasi; Ketiga, Kesamaan (Equality) yang mencakup kedudukan hukum, hak, dan kewajiban; Kempat, Kepribadian (Personality) seperti memiliki harga diri, rasa bangga, rasa sayang; Kelima, Prestasi (Achievement) merupakan cita-cita untuk mewujudkan kesejahteraan, kebesaran, serta kemanusiaan (Atmojo 2006:40).

Nasionalisme di Indonesia awal mulanya mulai disuarakan dan diorganisasikan pada dasawarsa kedua abad ke-20, tetapi unsur pokok nasionalisme sudah ditemukan pada periode sebelumnya. Nasionalisme bangkit ketika dampak dari kolonialisme Belanda yang dirasakan oleh bangsa Indonesia. 
Embrio nasionalisme dapat dikatakan laten dalam kelompok masyarakat Indonesia tetapi kenyataannya belum secara aktif dan dibiarkan terlalu lama karena belum ada unsur kepemimpinan (Kahin, 2013:55). Menjelang kemerdekaan Indonesia, Nasionalisme majemuk di Indonesia mulai digerakkan oleh kaum terpelajar baik dari lulusan luar negeri (Moh. Hatta, dkk) maupun dari dalam Negeri (Ir. Soekarno, dkk) mendapat pergolakan dan perdebatan dari sebagian golongan yang menghendaki agama (Islam) sebagai Ideologi Negara. Setelah melalui kompromi akhirnya perdebatan itu mulai menuai kesepakatan yaitu Pancasila sebagai dasar negara dengan perubahan pernyataan pada sila pertama. Pancasila ditetapkan sebagai dasar negara sekaligus sebagai ideologi negara, maka nasionalisme Indonesia bersifat inklusi-pluralis yang tidak mendasar pada ideologi agama atau nilai-nilai etnik tertentu (Muttaqin, 2006:30).

Pancasila sebagai dasar negara Republik Indonesia merupakan suatu asas kerokhanian yang meliputi suasana kebatinan atau cita-cita hukum, sehingga pancasila merupakan suatu sumber nilai, norma serta kaidah, baik moral maupun hukum negara, dan menguasai hukum dasar baik yang tertulis atau UUD maupun tidak tertulis atau convensi. Sedangkan pancasila sebagai ideologi negara Indonesia pada hakekatnya bukan merupakan suatu hasil pemikiran seseorang atau kelompok orang tetapi pancasila diangkat dari nilai-nilai adat-istiadat, nilai-nilai kebudayaan serta nilai religius yang terdapat dalam pandangan hidup masyarakat sebelum membentuk negara (Kaelan, 2010:110).

Dasar filosofi dari pancasila mengandung makna bahwa dalam setiap aspek kehidupan kebangsaan, kemasyarakatan serta kenegaraan harus berdasarkan nilai-nilai ketuhanan, kemanusiaan, persatuan, kerakyatan dan keadilan. Pada dasarnya negara adalah suatu persekutuan hidup manusia atau organisasi kemasyarakatan dalam hidup manusia atau masyarakat hukum. Pada hakekatnya kodrat manusia adalah sebagai makhluk Tuhan Yang Maha Esa (hakikat sila pertama). Negara merupakan persekutuan hidup manusia sebagai makhluk Tuhan Yang maha Esa bertujuan untuk mewujudkan harkat dan martabat manusia sebagai makhluk yang berbudaya atau makhluk yang beradap (hakikat sila ke dua). Terwujudnya suatu negara harus membentuk persatuan ikatan hidup bersama sebagai suatu bangsa (hakikat sila ketiga). Terwujudnya persatuan dalam suatu negara akan melahirkan rakyat sebagai suatu bangsa yang hidup dalam suatu wilayah negara tertentu. Sehingga dalam suatu negara harus bersifat demokratis hak serta kekuasaan rakyat harus dijamin baik secara individu maupun secara bersama (hakikat sila keempat). Untuk mewujudkan tujuan negara maka negara harus melindungi setiap warga negaranya berdasarkan suatu prinsip keadilan yang timbul dalam kehidupan bersama (hakikat sila kelima). Nilai-nilai inilah yang menjadi dasar bagi kehidupan kenegaraan, kebangsaan dan kemasyarakatan (Kaelan, 2012:26).

\section{SIMPULAN}

Nasionalisme merupakan suatu persekutuan hidup masyarakat yang berdiri sendiri dan masing-masing anggota tersebut merasa memiliki satu kesatuan ras, bahasa, agama, sejarah, dan adat istiadat. Suatu negara harus dijiwai dengan prinsipprinsip nasionalisme yaitu Kesatuan, Kebebasan, Kesamaan, Kepribadian, dan Prestasi. Nasionalisme merupakan tonggak perjuangan para pendiri bangsa dalam membentuk negara Indonesia yang merdeka dari kaum penjajah. Nasionalisme dirintis oleh para pejuang atau pendiri bangsa membentuk sebuah negara merdeka dengan pancasila sebagai ideologi negara sekaligus sebagai dasar negara.

Nasionalisme harus ditanamkan kepada generasi muda agar mengerti betapa penting sikap nasionalisme dalam membangun sebuah negara. Menanamkan sikap 
nasionalisme salah satu contohnya dengan mempelajari tentang nilai-nilai yang terkandung dalam batik Gebleg Renteng. Batik Gebleg Renteng merupakan kearifan lokal yang dimiliki oleh kabupaten Kulon Progo. Nilai filosofi batik Gebleg Renteng terdapat makna nasionalisme di dalamnya sehingga generasi muda atau siswa akan lebih mudah memahaminya. 
DAFTAR PUSTAKA

Aman, Toifful. (2014). Analisis Motif Batik Geblek Renteng Sebagai Motif Batik Khas Kulon Progo. Universitas Negeri Yogyakarta.

Atmojo, Dwi. Dkk. (2006). Nasionalisme Di Berbagai Negara. Yogyakarta: Universitas Sanata Darma.

Hosnan. (2014). Pendekatan Saintifik dan Kontektual dalam Pembelajaran Abad 21. Bogor

Kaelan, H. (2012). Pendidikan Kewarganegaraan untuk Perguruan Tinggi. Yogyakarta: Paradigma.

Kaelan. (2010). Pendidikan Pancasila, Pendidikan untuk mewujudkan Nilai-nilai Pancasila, rasa Kebangsaan dan Cinta Tanah Air. Yogyakarta: Paradigma.

Kahin, G.McT. (2013). Nasionalisme \& Revolusi Indonesia. Depok: Komunitas Bambu.

Muttaqin, Tatang. Dkk. 2006. Membangun Nasionalisme Baru: Bingkai Ikatan Kebangsaan Indonesia Kontemporer. Direktorat Kebudayaan, Pariwisata, Pemuda, Dan Olahraga Badan Perencanaan Pembangunan Nasional (BAPPENAS).

Silitonga, Felisia Meliana Ratri P. (2017). Strategi Pengembangan UMKM Batik Tulis (Studi Kasus Batik Tulis di Desa Gulurejo dan Desa Ngentak Rejo, Kecammatan Galur, Kabupaten Kulon Progo). Universitas Sanata Dharma Yogyakarta.

Wulandari, Ari. (2011). Batik Nusantara, makna filosofi, cara pembuatan \& industri batik. Yogyakarta: C.V Andi Offset.

Yatim, Badri. 1999. Soekarno, Islam dan Nasionalisme. Jakarta: Logos Wacana IImu. https://kulonprogokab.go.id/v31/detil/7687/identitas-daerah (23 Maret 2021)

https://motifbatik.web.id/2019/01/filosofi-dan-sejarah-batik-motif-geblek.html?m=1 Maret 2021) 